\title{
EPA feels heat over flame retardant
}

A much-anticipated report on the health hazards of a ubiquitous flame retardant has been delayed amid controversy over the removal of a respected toxicologist from the US Environmental Protection Agency (EPA) advisory panel reviewing the report.

The report, which was due last week, is expected to mount pressure on the chemical industry to ban decabrominated diphenyl ether (deca-BDE), which is used as a flame retardant in furniture, carpets, and televisions and other electronic goods. The EPA has delayed its release by a month and experts tracking the issue expect further delays. "It's been stuck at the White House Office of Management and Budget for months," says a frustrated EPA scientist who asked not to be named.

In February it emerged that the EPA had axed one of its senior toxicologists, Deborah Rice, from the panel's chair after an industry group, the American Chemistry Council (ACC), complained about her. A Freedom of Information Act request revealed that Rice was dismissed last year after the ACC questioned her objectivity. According to the EPA source, George Gray, an EPA official, removed Rice and struck all of her comments from the draft report.

Rice, now at the Maine Center for Disease Control and Prevention (CDC), had published research showing that deca-BDE can affect brain development in animals (D. C. Rice et al. Neurotoxicol. Teratol. 29, 511-520; 2007). As a Maine CDC employee, Rice testified about these harmful effects before the Maine state legislature, which subsequently banned the chemical (see 'Banned compounds'). Washington state had already banned deca-BDE, and other states are considering it. A 1 April court ruling has forced the European Commission to ban deca-BDE. Denmark and Sweden have also banned it.

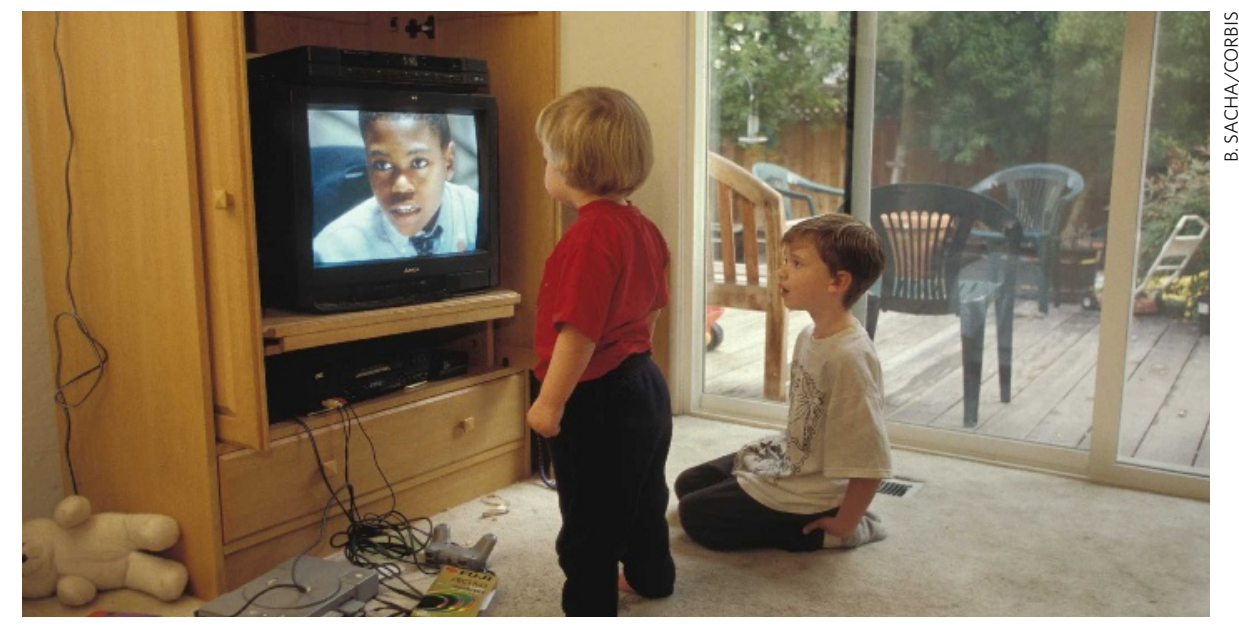

Deca-BDE is a flame retardant used in common household goods from televisions to carpets.

Rice's dismissal has incensed toxicologists within and outside the EPA. "In a word, it's outrageous," says Thomas Webster, who studies deca-BDE at the Boston University School of Public Health in Massachusetts. "She is a top toxicologist and her removal from the panel is utterly ridiculous."

One high-level EPA scientist who requested anonymity told Nature: "Many of us who work here are really angry about this."

Politicians are now stepping into the fray. On 17 March, the governor of Maine, John Baldacci, asked the EPA to reinstate Rice as chair of the panel and return her comments to the draft report. That same day, two Democratic Congressmen from Michigan, Bart Stupak and John Dingell, demanded an explanation from EPA administrator Stephen Johnson. "The ACC does not assert that Dr Rice had any pecuniary interest in the human health assessment at issue, and therefore seems to argue that scientific expertise with regard to a particular chemical ... is a basis for disqualification from a peer review board. This does not seem sensible on its face," the Congressmen write.

Their letter also names nine other members of EPA external review panels who either work for or receive funding from manufacturers of chemicals those same panel members were reviewing. "The routine use of chemical industry employees and representatives in EPA's scientific review process, together with EPA's dismissal of Dr Rice, raises serious questions" about how the EPA applies its conflict-of-interest rules, the letter states.

The letter asks for a response by $27 \mathrm{March}$, but on that day EPA associate administrator Christopher Bliley replied that "because of the large number of questions and requests for documents ... we are not able to provide you with a response at this time".

Brian Vastag

\section{Banned compounds}

Concern over the polybrominated diphenyl ether (PBDE) class of compounds surfaced in 1998, when Swedish researchers reported finding the compounds in stored breast milk. From 1972 to 1997, the concentrations of these chemicals in human milk had shot up 60-fold.

Toxicologists feared that the compounds' structural similarities to toxic, banned polychlorinated biphenyls (PCBs) meant the flame retardants might have a similar effect on the body.

Other work found that Americans carry much higher PBDE concentrations in blood and milk - as much as 100fold higher, in some studies - than Europeans. In addition, environmental sampling shows that the compounds persist for decades, finding their way into birds of prey and even polar bears. In 2004, in the face of growing toxicity data, the chemical industry agreed to stop making<smiles>Brc1c(Br)c(Br)c(Oc2c(Br)c(Br)c(Br)c(Br)c2Br)c(Br)c1Br</smiles><smiles>Clc1c(Cl)c(Cl)c(-c2c(Cl)c(Cl)c(Cl)c(Cl)c2Cl)c(Cl)c1Cl</smiles>

Deca-BDE (left) is similar to toxic, banned polychlorinated biphenyls. two classes of PBDEs, penta-BDE and octa-BDE, so named for the number of bromine atoms on their rings. But manufacturers continue producing large quantities of deca$\mathrm{BDE}$, the fully brominated version of the basic molecule.

Manufacturers claim that
deca-BDE saves 300 lives a year in the United States by preventing or slowing house fires. But some researchers dispute that figure. "It's really difficult to know how many lives are saved by it," says Daniele Staskal, a toxicologist at the consulting firm ChemRisk. B. V. 